\title{
Perceived marketing intelligence and marketing communications tools used by rural Small, Medium and Micro Enterprise in South Africa
}

\author{
Lawrence Mpele Lekhanya \\ Durban University of Technology, South Africa \\ lawrencel@dut.ac.za
}

\begin{abstract}
Previous research revealed that Small, Medium and Micro Enterprises (SMMEs) have been struggling to grow including in rural and remote areas. However, there is little empirical research into how SMMEs promote themselves. To date is not clear about what marketing intelligence and marketing promotional communications they use. The survey intends looking to make contribution in closing research gap by seeking to understand the marketing intelligence and marketing promotional communications tools used by rural SMMEs and to what extent they used these tools and what are the limitations they have. This research aims to examine the perceived marketing intelligence and marketing communications tools used by South African rural SMMEs, to identify limiting factors to the used and establish the extend to use and their implications. The study population consisted of 374 respondents in five rural areas of KwaZulu - Natal province in South Africa (Empangeni, Ulundi, Nquthu, Escourt and Kwa-Nongoma). A quota sampling method was used to determine desired target population. Quantitative Likert scale questionnaire was designed and personal distributed to the respondents. Respondents were giving 7 days to complete questionnaire. Data analysis was done using SPSS (21.0) version. Figures and tables were used to present research findings. Statistical analysis revealed that marketing intelligence and marketing promotional tools were applied and found to be significant. The study found that promotional communication tools that cover both marketing promotional mix and marketing intelligence used by rural SMMEs are significant $\left(\mathrm{p}=.000^{*}\right)$
\end{abstract}

Keywords: Small, Medium and Micro Enterprise; marketing intelligence; rural; tools; Perceived; marketing communications

\section{Introduction}

Zikmund (1996) describe marketing intelligence as a network of source and regular procedures by which marketing executives obtain everyday information about non recurrent development in the external marketing environment. On the other hand, according to Ettorre (1995), marketing intelligence is the process of gathering significant information about competitors, their position in the marketplace, their core competencies and applying this knowledge for achieving distinctive competencies and executing short and long term planning. Furthermore, Fao.org (2010) defines marketing intelligence system as a set of procedures and data sources used by marketing managers to sift information from the economic and business environment that they can apply in their decision making. While, Odunlami \& Ofoegbu (2011) define marketing communication as the promotional tools that can be used to communicate favourable information about the organization and its products to the target market. Ailawadi, Beauchamp, Donthu, Gauri \& Shankar, 2009) stress that communication and promotion decisions are a fundamental part of retailer customer experience management strategy. However, SMMEs owners/managers need to get proper information about the target market they want to serve before they can put marketing communications strategies in place. This means that SMMEs have to manage their marketing intelligence effectively and sufficiently. However, Kotkar, Itankar, Ghodghate \& Rewatkar (2013) believe that marketing communication is continuous interaction between the buyers and sellers in a market place. Mohammadsaid \& Freihat (2012) echoed the sentiment that since marketing decisions are affected by many internal and external environmental factors, getting marketing information through marketing communication mix and the use of marketing intelligence is very important. They believe that businesses require a dynamic rather than static view of the market intelligence as opposed to market research.

Problem statement: It has been indicated that some of small retailers had no interest in utilising integrated marketing communications to promote their businesses (Mapheto, Oni \& Matiza, 2014). Literature shows that there is little work that has been done to date with regard to significance use of marketing communications and marketing intelligence in the context of small, medium and micro 
enterprises (SMMEs) (Kotler, 2005). Therefore, this is not the case in the South African rural SMMEs. It has been fund that SMMEs owners/managers in rural KwaZulu -Natal are not utilizing most of marketing promotional tools and also they lack marketing information support mechanisms in their areas (Lekhanya \& Mason, 2013). Rural SMMEs frequently lack proper planning in promoting their products and services (Tsikirayi, Muchenje \& Katsidzira, 2012).

\section{Aims and Objectives}

The main focus of the study is to add more on discussion about the promotion of rural SMMEs to contribute to their survival and growth as they are important to the economic development of South Africa.

- To determine the perception of SMMEs owners/mangers with regard to the marketing intelligence and marketing communication tools they use in rural KZN.

- To examine availability and use of marketing intelligence of SMMEs owners/managers in rural KZN.

- To assess the extent to which marketing promotional communication tools such as public relations are applied by rural SMMEs in KZN.

\section{Literature review}

SMME marketing in rural places: It is presumed that basic marketing principles are relevant to any kind of enterprise, regardless of its dimension (Gabrielli \& Balboni, 2010). Nwankwo \& Gbadamosi (2011) stress those marketing theories applied to large enterprises are considered valuable for SMMEs as well. However, Bechere, Halstead \& Haynes (2001), marketing orientation as a culture in which organizations strive to create superior value for their customers by focusing on customer needs and long-term profitability. Research has shown that an integration of marketing in the SMMEs still lacking. According to Carson \& Gilmore (2000), SMME marking mix which has been adopted from traditional marketing 4Ps can improve SMMEs and can be also an integral part of SMMEs activities.

Integrated marketing communication concept of rural SMMEs: According to Walker, Mullins, Boys \& Larreche (2006), the marketing concept, is one of the most lasting concepts in marketing theory, which states that satisfying customer needs will lead to the achievement of organisational goals such as profitability. This means that all company activities should be properly planned and well-coordinated in order to meet primary goal of satisfying customer needs and sustain competitive advantage. The research shows that SMMEs managers tend to adapt IMC in order to grasp opportunities on the market, rather than planning and communicating the values related to the product in an integrated way (Esposito, 2013). Reijonen \& Laukanen (2010) indicated that the importance of marketing competences and training that are absolutely necessary to make the most effective and efficient use marketing communications such as internet.

Integrated Marketing communication orientation of rural SMMEs: according to Becherer, Halstead \& Haynes (2001), it has been noticed that external environment has big influence on the marketing orientations of SMMEs. They also believe that SMMEs are affected by their own internal culture as smaller firms are less bureaucratic which reflects their own specific leadership and internal circumstances. Reijonen \& Laukanen (2010) maintain that there is a great difference in the activity of different marketing tasks in SMMEs including the customer relationships development as well as pursuing profitable customers, whereas other marketing communication tasks such as segmentation and differentiation are less carried out by SMMEs owners/managers. However, Shoham, Rose \& Kropp (2005) argue that there is a strong theoretical support that market orientation is how the marketing concept manifests itself in the organisation which leads to superior performance. They indicate that market orientation is highly dependent on the generation and dissemination of marketing intelligence to marketing decision-makers and influencers, and responses by decision-makers to marketing intelligence.

Why integrated marketing communication for rural SMMEs: Wong \& Merrilees (2005) state that marketing ideas, concepts and techniques are useful if applied properly. The most widespread communication purpose is to activate dialogues and new connections with their stakeholders and the most used communication tools are participation in fairs, sponsorships and events, but the very emerging tool is online communication: digital and social media (Esposito, 2013). Many SMMEs lack clear 
understanding of the important role played by the marking communications mix in creating awareness of their products and service to the potential customers (Tsikirayi, Muchenje \& Katsidzira, 2012)

Marketing Intelligence: Smith (2011) defines marketing intelligence (MI) as the process of gathering information in the field of business and thus allows business managers to fast-track decision making process. This process provides company with more detailed information which include the broad understanding of what is happing in the marketplace, what the issues are and what the likely market potential is. According to Igbaekemen (2014), marketing intelligence system is an important instrument in gathering relevant information for the marketing managers, executives and managements in making decision under certainty, uncertainty and risk.

Types of Marketing Intelligence: Marketing intelligence classified into two categories frequently based on external data and internal data (Smith, 2011). Internal data marketing intelligence includes online transaction processing, clickstreams data and reports from internal sources, while external data includes primary sources, human intelligence, observation and secondary public domain sources (Venter \& van Rensburg, 2014).

Importance of Marketing Intelligence: Organizations have to embark on efficient and effective marketing intelligence in order to maintain their competitive position in the industry in light of this (Igbaekemen, 2014). The term intelligence includes important meanings in business environments. The existence of good source of business intelligence signifies the survival of businesses, which can range from data about their existing customers to intelligence about their competitors (Maguire \& Robson, 2005, in Slimani, 2013). Marketing intelligence provides small business companies with information from the business environment for decision making. This information includes external or internal such as political, economic, technological and socio-cultural elements and it is also include information on customer demographics and competitors (Suttle, 2009). An integrated marketing strategy 2012 to 2030 (2014) stipulates that market intelligence can be collected through desk research and by identifying competitors and analysing their market position, this include identifying market prospects, partners as well as collecting information on competitors.

SMMEs use of marketing intelligence: literature indicates the gap between the theory and practice of market intelligence gathering within the SMMEs (Ross, McGowan \& Styger, 2012). Strategic approach to characterise and determine information for SMMEs depends on the firm size and resource allocation. However, it has been noticed that SMMEs engage in very little formal intelligence gathering as mostly they use external consultants (Venkatesan, 2001).

\section{Summary of key questions}

\begin{tabular}{ll}
\hline Research Area & Question \\
\hline Methods of promotion & $\begin{array}{l}\text { The following methods of promotion were used in the past 12 month's period. } \\
\text { Alternative response: personal selling; National advertising; Competitions; } \\
\text { Sponsorship; Special offers; Local advertising; Public relations; and None of } \\
\text { the above }\end{array}$ \\
$\begin{array}{l}\text { Management services } \\
\text { availability }\end{array}$ & $\begin{array}{l}\text { Please indicate from the following fields in which you have received training? } \\
\text { Alternative response: Building and Construction manager; Human resource } \\
\text { manager; Business manager; Marketing manager. }\end{array}$ \\
$\begin{array}{l}\text { Which of the following services are available in your area? } \\
\text { Sources of marketing } \\
\text { information }\end{array}$ & $\begin{array}{l}\text { Response alternative: Marketing research agency; Marketing consultants; } \\
\text { Marketing agency; Advertising Agency; and None of the above }\end{array}$ \\
\hline
\end{tabular}

\section{Methodology}

The major source of information from which to formulate the research questionnaire was the literature review, which was used to form closed -ended.

Target population: Research questionnaire was formulated and used to collect primary data from 374 SMMEs owners/managers operating in the selected areas in rural KZN regarding their perceptions of marketing intelligence and marketing communications tools they use in their rural areas. The study was limited to the KwaZulu-Natal rural areas only. These selected rural areas were chosen due to their profile characteristics that represent racial groups suitable for the study. 
Questionnaire administration: The research assistants were recruited and trained to make sure that questionnaires were completed under the same and good conditions. Period of 7 days were giving to the respondents to complete the questionnaire. Same instructions were giving in all questionnaires. To manage inconsistency in coding, all questionnaires were pre-coded.

Analysis of research data: The research data analysis was done through the use of statistical package for social sciences (SPSS) version 21.0. Descriptive and inferential statistics were determined. Results were presented in the cross-tabulations. Test of relationship of the variables was performed by conducting a chi-square goodness of fit test.

Reliability and validity: The results were found to be very significant at .0820 when Cronbach's 0.75 was applied to test significance of the results.

\section{Findings}

A comprehensive literature review was done to demonstrate rural SMME marketing communications tools and how they are used. Therefore, the following section reports on the key findings of this study, based on the response from 374 respondents $(\mathbf{n}=\mathbf{3 7 4})$ who either SMMEs' owners/ managers.

Table 1: The Mean Rank Score for Respondents

\begin{tabular}{llllllllll}
\hline & & $\mathbf{N}$ & percentage & Mean & $\begin{array}{l}\text { Std. } \\
\text { Deviation }\end{array}$ & $\begin{array}{l}\text { Mean } \\
\text { Rank }\end{array}$ & $\begin{array}{l}\text { Mann } \\
\text { Whitney U }\end{array}$ & $\mathbf{z}$ & P \\
\hline Local & Yes & 214 & $57.2 \%$ & 3.89 & .621 & 198.78 & 14279.000 & -.572 & .010 \\
advertising & No & 158 & & 3.74 & .686 & 169.87 & & & \\
National & Yes & 40 & $10.7 \%$ & 4.06 & .568 & 231.38 & 4845.000 & -.804 & .005 \\
Advertising & No & 332 & & 3.80 & .658 & 181.09 & & & \\
Sponsorship & Yes & 12 & $3.2 \%$ & 3.81 & .685 & 188.25 & 2139.000 & -.058 & .954 \\
& No & 360 & & 3.83 & .653 & 186.44 & & & \\
Brochures & Yes & 157 & $42.0 \%$ & 3.93 & .553 & 200.29 & 14712.500 & -.121 & .034 \\
& No & 215 & & 3.75 & .710 & 176.43 & & & \\
Personal & Yes & 149 & $39.8 \%$ & 3.93 & .592 & 204.00 & 14005.500 & -.575 & .010 \\
selling & No & 223 & & 3.76 & .683 & 174.80 & & & \\
Competitions & Yes & 67 & $18.2 \%$ & 4.25 & .332 & 260.60 & 5252.500 & -.252 & .000 \\
& No & 305 & & 3.73 & .670 & 170.22 & & & \\
Special offers & Yes & 159 & $42.5 \%$ & 3.99 & .499 & 211.37 & 12979.000 & -.868 & .000 \\
& No & 213 & & 3.71 & .726 & 167.93 & & & \\
Public & Yes & 93 & $24.9 \%$ & 4.03 & .522 & 216.94 & 10143.000 & -.163 & .002 \\
relations & No & 279 & & 3.76 & .679 & 176.35 & & & \\
Other printed & Yes & 68 & $18.3 \%$ & 3.84 & .653 & 189.17 & 10154.500 & -.227 & .820 \\
Materials & No & 304 & & 3.82 & .654 & 185.90 & & & \\
\hline
\end{tabular}

The findings of the study shown in Table1 reveals that the mean rank score for respondents use of local advertising or not use indicates the high significant amongst those who use local advertising as opposed to those who don't at the 95\% level $(\mathrm{p} \leq 0.05)$. This suggest that those who use local adverting have a higher degree of positive perception that those who don't use local advertising. Other elements such as personal selling, public relations, competition, national advertising, and brochures have positive perception. Those who use sponsorships and those who don't have the same degree of positive perception while there is no significant different between those who use other printed materials as opposed to those who don't at the 95\% level.

Table 2: SMMEs marketing sources in rural KZN

\begin{tabular}{lll}
\hline Variables & Frequency & Percentages \\
\hline Marketing research agency & 364 & $97.3 \%$ \\
Marketing consultants & 345 & $92.2 \%$ \\
Marketing agency & 353 & $94.4 \%$ \\
Advertising agency & 295 & $78.9 \%$ \\
None of the above & 10 & $2.7 \%$ \\
\hline
\end{tabular}


Table 2 indicates that, contrary to the literature survey, there were marketing support services in the rural areas. Therefore, the lack of marketing support is unlikely to be a reason for rural SMMEs not doing marketing in the KwaZulu-Natal rural areas. However, only a few SMMEs (2.7\%) indicated that there were no marketing services in their areas. A Chi-square goodness of fit, which was conducted with regard to availability of professional services including marketing services in rural KZN, was based on a null hypothesis of uniformity of expected responses to the question. The results $(X 2=335.070, d f=1, p=.000)$ indicated that the observed findings were significantly different from the expected frequencies. In other words, this result was statistically significant and was not due to chance.

Table 3: Services that available in the areas of the respondents providing information for business

\begin{tabular}{lll}
\hline Variable & Frequency & Percentage \\
\hline Marketing managers & 77 & $20.4 \%$ \\
Human resource managers & 278 & $73.7 \%$ \\
Business managers & 160 & $42.6 \%$ \\
Building and construction managers & 346 & $91.8 \%$ \\
\hline
\end{tabular}

Table 3 shows that the majority of respondents across industries have training in different management areas and a small number (20.4\%) have training in marketing management. There are good levels of training in human resource management, business management and building and construction management $(73.7 \%, 42.4 \%$ and $91.8 \%)$, respectively. A Chi-square goodness of fit was conducted on training and the type of business. This question was based on a null hypothesis of uniformity of expected responses to the question. The result $(\mathrm{X} 2=129.412, \mathrm{df}=1, \mathrm{p}=.000)$ indicated that the observed findings were significantly different from the expected frequencies. In other words, this result was statistically significant and was not due to chance.

Table 4: Binomial results

\begin{tabular}{|c|c|c|c|c|c|}
\hline & & Category & $\mathbf{N}$ & $\begin{array}{l}\text { Observed } \\
\text { Prop. }\end{array}$ & $\mathbf{P}$ \\
\hline \multirow[t]{3}{*}{ Local advertising } & Category1 & No & 160 & $42.8 \%$ & \\
\hline & Category 2 & Yes & 214 & $57.2 \%$ & 0.006 \\
\hline & Grand total & & 374 & & \\
\hline \multicolumn{2}{|c|}{ National advertising Category 1} & No & 334 & $89.3 \%$ & \\
\hline & Category 2 & Yes & 40 & $10.7 \%$ & 0.000 \\
\hline & Grand total & & 374 & & \\
\hline \multirow[t]{3}{*}{ Sponsorship } & Category 1 & No & 362 & $96.8 \%$ & \\
\hline & Category 2 & Yes & 12 & $3.2 \%$ & 0.000 \\
\hline & Grand total & & 374 & & \\
\hline \multirow[t]{3}{*}{ Brochures } & Category 1 & No & 217 & $58.0 \%$ & \\
\hline & Category 2 & Yes & 157 & $42.0 \%$ & 0.002 \\
\hline & Grand total & & 374 & & \\
\hline \multirow[t]{3}{*}{ Personal selling } & Category 1 & No & 225 & $60.2 \%$ & \\
\hline & Category 2 & Yes & 149 & $39.8 \%$ & 0.000 \\
\hline & Grand total & & 374 & & \\
\hline \multirow[t]{3}{*}{ Competitions } & Category 1 & No & 306 & $81.8 \%$ & \\
\hline & Category 2 & Yes & 68 & $18.2 \%$ & 0.000 \\
\hline & Grand total & & 374 & & \\
\hline \multirow[t]{3}{*}{ Special offers } & Category 1 & No & 215 & $57.5 \%$ & \\
\hline & Category 2 & Yes & 159 & $42.5 \%$ & 0.004 \\
\hline & Grand total & & 374 & & \\
\hline \multirow[t]{3}{*}{ Public relations } & Category 1 & No & 281 & $75.1 \%$ & \\
\hline & Category 2 & Yes & 93 & $24.9 \%$ & 0.000 \\
\hline & Grand total & & 374 & & \\
\hline \multicolumn{2}{|c|}{ Other printed materials Category 1} & Yes & 70 & $18.7 \%$ & \\
\hline & Category 2 & No & 304 & $81.3 \%$ & 0.000 \\
\hline & Grand total & & 374 & & \\
\hline \multirow[t]{3}{*}{ None of the above } & Category 1 & No & 356 & $95.2 \%$ & \\
\hline & Category 2 & Yes & 18 & $4.8 \%$ & 0.000 \\
\hline & Grand total & & 374 & & \\
\hline
\end{tabular}


Table 4 shows the significant difference in the proportions of respondents who use local advertising, national advertising and other media. The proportion of respondents who use local advertising (57.2\%) is significantly higher at the $95 \%$ level.

Limitations: Many SMMEs from the Southern part of KZN were not researched, so this leaves the gap for this study as the area covers big municipalities in KwaZulu -Natal province. Furthermore, the study was mainly focused on the registered SMMEs without taking account those who are not registered and also did not include small cooperatives in these areas. A structured questionnaire was used which was in fact limiting respondents to express their opinion in more details regarding other critical issues that they might be aware off.

Managerial implications for the study: With regard to the findings revealed by this survey, there are considerable practical implications of this study. The study offers useful information to the SMMEs owners/managers with regard to perceived marketing intelligence and marketing communications tools use by rural SMMEs in South. The results indicate that respondents who use local advertising have higher degree of positive perception than those who don't use local advertising. This followed by other elements including personal selling, national advertising as well as brochures as the most frequently use marketing promotional tools.

\section{Conclusion}

This study tried to examine respondents' perceived marketing intelligence and identify most marketing communication tools used by the rural SMMEs in South Africa with specific reference in rural KwaZulu Natal. The study found that not all elements of marketing communication utilized by SMMEs even although they know about them. They however associate the use of marketing tools with big companies and being very expensive for their businesses.

Recommendations: In order to enable SMMEs to overcome the challenges faced by SMMEs owners/managers in rural areas. South African government should implement Small business mentorship programme policy that is outlined in the strategic national growth plan more especially in the rural areas. Entrepreneurial education must be included in the high school's curriculum where learners will be introduced in various subjects such business management, financial management, information systems and marketing management. Government should run workshops through community centres which include the important and how to use ICT to promote the business in rural and remote places. Government should provide consultative services including marketing consulting and marketing agencies for the rural communities this can be done through the local district office in each rural district for social and community development.

\section{Reference}

Ailawadi, K. L., Beauchamp, J. P., Donthu, N., Gauri, D. K. \& Shankar, V. (2009). Communication and Promotion Decisions in Retailing: A Review and Directions for Future Research. Journal of Retailing, 85(1), 42-55.

An integrated marketing strategy 2012 to 2030. (2014). An Integrated Marketing Strategy for Agriculture Forestry and Fisheries Products in the Republic of South Africa, 2012-2030. [Online]. Available at:http://www.nda.agric.za/doaDev/sideMenu/Marketing/Policies\%20and\%20Strategies/An \%20Integrated\%20Marketing\%20Strategy\%20for20Agriculture\%20Forestry\%20and\%20Fish eries\%20Products\%20in\%20the\%20Republic\%20of\%20South\%20Africa.pdf (Accessed 21/03/2014).

Becherer, R. C., Halstead, D. \& Haynes, P. (2001). Marketing Orientation in SMEs: 1 - 17. Journal of Research in Marketing \& Entrepreneurship, 3(1).

Carson, D. \& Gilmore, A. (2000). Marketing at the interface: not 'what?' but 'how? Journal of Marketing Theory and Practice, 8(2), 1-7.

Esposito, A. (2013). Insights about Integrated Marketing Communication in Small- and Medium-Sized Italian Enterprises. Business Systems Review, 2 (1), 80-98.

Ettorre, B. (1995). Managing Competitive Intelligence. Management Review, 15-19.

Fao.Org. (2010). Marketing information systems. [Online]. Available at: www.fao.org/docrep/w3241e/w3241e0a.htm (Accessed 18/08/2014). 
Gabrielli, V. \& Balboni, B. (2010). SME Practice towards Integrated Marketing Communications. Marketing Intelligence \& Planning, 28(3), 275-290.

Igbaekemen, G. O. (2014). Marketing intelligence as a strategic tool for competitive edge. British Journal of Marketing Studies, 2(5), 17-34.

Kotkar, M., Itankar, S., Ghodghate, N. \& Rewatkar, S. (2013). Effective Utilization of Marketing Communication Channel by FMCG Retailers of Rural India, International Journal of Application or Innovation in Engineering \& Management (IJAIEM): Special Issue for National Conference on Recent Advances in Technology and Management for Integrated Growth 2013 (RATMIG 2013

Kotler, P. (2005). Marketing management (13th edition), Harvard business review, Prentice Hall

Lekhanya, L. M. \& Mason, R. B. (2013). The use of marketing strategies by small, medium and micro enterprises in rural KwaZulu-Natal, SAJESBM, 6,

Mapheto, L. M., Oni, O. A. \& Matiza, T. (2014). the Utilisation of Integrated Marketing Communication Strategies by Small Retailers in Mankweng, South Africa. Mediterranean Journal of Social Sciences, MCSER Publishing, Rome-Italy, 5(15).

Mohammadsaid, S. \& Freihat, S. (2012). The role of marketing information system in marketing decisionmaking in Jordanian shareholding medicines production companies. http://www.arpapress.com/volumes/vol11issue2/ijrras_11_2_18.pdf (Accessed 19/08/2014).

Nwankwo, S. \& Gbadamosi, A. (2011). Entrepreneurship Marketing Principles and Practice of SME Marketing. Oxfordshire: Routledge

Odunlami, I. \& Ofoegbu, O. E. (2011). Effect of Marketing Communication in Promoting Organisational Sales. A Case Study of Sunshine Company. Journal of Emerging Trends in Economics and Management Sciences, 2(5), 408-412

Reijonen, H. \& Laukkanen, T. (2010). Customer relationship oriented marketing practices in SMEs. Marketing Intelligence \& Planning, 28(2), 115 - 136.

Ross, P., McGowan, C. G. \& Styger, L. E. J. (2012). A Comparison of Theory and Practice in Market Intelligence Gathering for Australian Micro-Businesses and SMEs, [Online].Available at: http://papers.ssrn.com/sol3/papers.cfm?abstract_id=2253691 (Accessed 19/08/2014)

Shoham, A., Rose, G. M. \& Kropp, F. (2005). Market orientation and performance: a meta- analysis. Marketing Intelligence \& Planning, 23(4/5), 435-454.

Slimani, T. (2013). Concepts and Tools for Marketing Intelligence Development, http://www.igiglobal.com/article/concepts-and-tools-for-marketing-intelligenc development/80173 (Accessed 27/08/2014).

Smith, 0. (2011). The power of marketing intelligence, [Online]. Available at: http://www.smetimes.in/smetimes/in-depth/2011/May/31/the-power-of-marketing intelligence354533.html (Accessed 18/08/2014).

Suttle, R. (2009).Three Examples of Marketing Intelligence._http://smallbusiness.chron.com/threeexamples-marketing-intelligence-25483.html (Accessed 27/08/2014).

Tsikirayi, C. M. R., Muchenje, B. \& Katsidzira, Z. (2012). Impact of integrated marketing communications mix (IMCM) in small to medium enterprises (SMEs) in Zimbabwe as a marketing tool, Research in Business and Economics Journal,

Venkatesan, V. S. (2001). Market research in Australian SMEs: An empirical study. The Journal of SEAANZ, $9(2)$.

Venter, P. \& Van Rensburg, M. (2014).The relationship between marketing intelligence and strategic marketing. SAJEMS NS, 17(4), 440-4.

Walker, D. C. Jr., Mullins, J. W., Boyd, H. W. Jr. \& Larreche, J. C. (2006). Marketing strategy: a decisionfocused approach. 5th edition, New York, NY: McGraw-Hill Irwin.

Wong, H. \& Merrilees, B. (2005). A brand orientation typology for SMEs: a case research approach. Journal of Product \& Brand Management, 14(3), 155 - 162.

Zikmund, W. G. (1996). Exploring Marketing Research. The Dryden Press, Fort Worth, TX. 